\title{
FRACTAIS DO ENSINO DE HISTÓRIA: UM PANORAMA DA PRODUÇÃO ACADÊMICA SOBRE A HISTÓRIA LOCAL (2009-2019)
}

\author{
FRACTS OF HISTORY TEACHING: A PANORAMA OF ACADEMIC \\ PRODUCTION ON LOCAL HISTORY (2009-2019)
}

\author{
Ocimara Fernandes Negreiro Oliveira ${ }^{1}$ \\ http://lattes.cnpq.br/5468785680500181 \\ https://orcid.org/0000-0002-6259-4639
}

Paulo Augusto Tamanini2

http://orcid.org/0000-0001-6963-2952

http://lattes.cnpq.br/2405551882781242

\section{Francisco da Vieira da Silva 3 \\ http://orcid.org/0000-0003-4922-8826 \\ http://lattes.cnpq.br/8730615940772209}

Recebido em: 16 de fevereiro de 2020

Aprovado em: 11 de agosto de 2020

RESUMO: O presente trabalho apresenta um mapeamento da produção acadêmica sobre a História Local no Brasil entre os anos de 2009 a 2019, com o intuito de conhecer o que vem sendo produzido sobre a temática. Metodologicamente, temos uma pesquisa descritiva, com uma abordagem qualitativa que resultou em um estado da arte, inventariado a partir do Catálogo de Teses e Dissertações da CAPES, da Revista de História da USP, da Revista História. Para além de planificar as produções acerca do que vem sido discutido no meio acadêmico sobre a História Local, tecemos considerações sobre possibilidades de abordagem, de métodos de ensino e pesquisa que cercam a História Local. Os resultados, ainda que parciais, mostram uma baixa produção sobre o tema, o que nos leva a refletir sobre a importância de dinamizar, produzir e divulgar mais estudos, abrindo caminhos para novas empreitadas investigativas, sobretudo, a relação da História Local com o Ensino.

Palavras-chave: História Local. Ensino de História. Academia.

\footnotetext{
${ }^{1}$ Mestranda do Programa de Pós-Graduação em Ensino (POSENSINO), da Universidade Estadual do Rio Grande do Norte (UERN), Universidade Federal Rural do Semi-Árido (UFERSA) e Instituto Federal de Educação, Ciência e Tecnologia do Rio Grande do Norte (IFRN). Professora da rede municipal de ensino de Mossoró - RN. Membro do Grupo de Pesquisa Imagem e Ensino. E-mail: oci_mara@hotmail.com.

2 Pós-Doutor em História pela Universidade Federal do Paraná (UFPR). Doutor em História pela Universidade Federal de Santa Catarina (UFSC). Professor do Programa de Pós-Graduação em Ensino - POSENSINO (UERN/UFERSA/ IFRN). Coordenador do Grupo de Pesquisa Imagem e Ensino (CNPq/UFERSA). E-mail: professor@tamanini.com.br.

${ }^{3}$ Docente da Universidade Federal Rural do Semi-Árido (UFERSA) e do Programa de Pós-Graduação em Letras (PPGL) da Universidade do Estado do Rio Grande do Norte (UERN) e do Programa de Pós-Graduação em Ensino (POSENSINO) da associação entre a Universidade do Estado do Rio Grande do Norte (UERN), a Universidade Federal Rural do Semi-Árido (UFERSA) e o Instituto Federal de Educação, Ciência e Tecnologia do Rio Grande do Norte (IFRN). E-mail: francisco.vieiras@ufersa.edu.br.
} 
ABSTRACT: The present work presents a mapping of academic production on Local History in Brazil between the years 2009 to 2019, in order to know what has been produced on the theme. Methodologically, we have a descriptive research, with a qualitative approach that resulted in a state of the art, inventoried from the CAPES Thesis and Dissertations Catalog, from USP's History Magazine, from History Magazine. In addition to planning the productions about what has been discussed in academia about Local History, we make considerations about possibilities of approach, teaching and research methods that surround Local History. The results, although partial, show a low production on the theme, which leads us to reflect on the importance of dynamizing, producing and disseminating more studies, opening paths for new investigative endeavors, above all, the relationship between Local History and Teaching.

Keywords: Local History. History Teaching. Academy.

\section{INTRODUÇÃO}

A História Local oportuniza ao aluno uma compreensão do lugar no qual ele vive, se socializa e constrói sua percepção de mundo. Mundo este que não está deslocado do passado, tão pouco das especificidades de um determinado espaço que, sobre ele reverbera o que no global se decide, acontece ou se discute. Atenta a isso, a Lei de Diretrizes e Bases da Educação Nacional (LDB, Lei no 9.394/1996) principia que o currículo escolar precisa contemplar conhecimentos comuns no campo nacional bem como os de características regionais e locais. Portanto, o ensino formal está responsável por lidar não só com os saberes gerais ou de cunho nacional, mas também com aqueles mais específicos que remetem a uma determinada região ou lugar.

Professores de História perceberam que o ensino de História Local também auxiliava na compreensão das identidades de seus alunos (ainda que estas sejam complexas, múltiplas, variáveis); que o ensino de História Local contribuía para entender os acontecimentos fundantes de suas cidades ou bairros, ajudava na percepção de que os espaços das vivências e sociabilidades dos alunos tinham um rastro, uma importância historiográfica. Portanto, temáticas locais que, segundo Freire (1996) auxiliam na aprendizagem efetiva do conhecimento que, longe de serem abstratas, devem se tornar tangíveis, instigantes e integrantes do cotidiano dos alunos. Desta maneira, a História Local mostra-se, então, um objeto de estudo interligado à realidade do aluno em seu espaço de convivência, valorizada por lastro de interesse social e que reverbera no próprio espaço formativo das escolas.

O ensino da História Local não ensina sobre o passado sozinho. A ele se integram os conhecimentos interdisciplinares, uma vez que ainda não é possível desassociar contextos por vezes, políticos, por vezes, religiosos, por vezes culturais do cotidiano e que se prestam para juntos tecer uma História que pode ser vista e lida sob múltiplas perspectivas. Isto porque a História, como área de conhecimento e de Ensino jamais pode ser compreendida enquanto promotora de uma só visão do passado. Antes, deve apresentar o acontecido de forma também aberta e receptiva, tornando possível que alunos possam contribuir para a construção de um conhecimento em que ele próprio é partícipe. Portanto, trabalhar a História Local de forma interdisciplinar e inclusiva é conduzir o ensino para os múltiplos olhares da formação humana (BAUER, 2012), é respeitar o outro em seu exercício de cidadania participativa.

É necessário então que os professores ensinem a História Local tendo a convicção da im- 
portância das particularidades que ajudam na compreensão da totalidade. Uma não pode excluir a outra. Ambas se completam e complementam. Por isso, o ensino de História Local é promissor porque capaz de aproximar o aluno de a sua realidade, modificando aquele pensamento equivocado e, quase que cristalizado entre os discentes, de que aprender História não serve para nada!

Na Base Nacional Comum Curricular (BNCC), por exemplo, a História Local é requerida numa das habilidades relativas à caracterização e compreensão dos ciclos da história republicana. Além das competências gerais a BNCC observa que é necessário "valorizar e utilizar os conhecimentos historicamente sobre o mundo físico, social, cultural e digital para entender e explicar a realidade local, continuar aprendendo e colaborar para a construção de uma sociedade mais justa, democrática e inclusiva” (BRASIL, 2017, p. 11). Ora, a valorização dos aspectos locais na educação formal está intrinsecamente relacionada a apreensão dos saberes construídos sobre os aspectos físicos, sociais e culturais do contexto local, tendo em vista que este é o espaço primeiro com o qual o discente lida e, a partir dele, poderá explorar e compreender conhecimentos acerca de outros espaços e tempos.

Mas, se o ensino de História Local tem ganhado prevalência, como ele se dá na prática? Qual o interesse dos pesquisadores em tornar a temática de História Local objeto de suas pesquisas na área da Educação?

Destas inquietações nasceu o objetivo desse escrito: mapear e inventariar a produção acadêmica sobre a História Local no Brasil nos anos de 2009 a 2019, com o intuito de se conhecer sob quais aspectos ela vem sendo explorada.

Para tanto, essa pesquisa é descritiva e de abordagem qualitativa, o que resultou em um estado da arte inventariado a partir das Dissertações, Teses e Artigos acadêmicos publicadas o Catálogo de Teses e Dissertações da CAPES, na Revista de História da USP, na Revista História e Ensino e no Projeto Político Pedagógico de três escolas de Mossoró - RN. A escolha do Portal e dos Periódicos justifica-se por serem referências de divulgação digital e de fácil acesso aos trabalhos já submetidos às Bancas de defesa ou às avaliações às cegas, feitas por pares.

Estruturamos o nosso trabalho em quatro tópicos. No primeiro, apresentamos as discussões mais recentes sobre a História Local em sala de aula, apoiando-nos em teóricos como Bittencourt (2008) para discutir a respeito da estrutura curricular no ensino de História; Freitas (2010) para discutir acerca da formação crítica do cidadão; Guimarães (2011) para expandir a compreensão de História Local; e, por fim, Fazenda (1994) e Japiassu (1994) com conceitos de interdisciplinaridade e História Local.

No segundo, trazemos a produção acadêmica sobre a História Local, ancorados nos estudos de Ferreira (2002) e Romanowski e Ens (2006) sobre o estado da arte e estado do conhecimento, envolvendo definições, diferenciações e construções. Mapeamos, filtramos e catalogamos as Dissertações e Teses defendidas e que se tronaram para esta pesquisa o corpus documental a partir do qual se estruturam as ponderações.

No terceiro, apresentamos alguns resultados acerca dos oito trabalhos encontrados, somados a nossa percepção de professores e pesquisadores.

Por fim, trazemos nossas considerações finais demonstrando as dificuldades de se ensinar a História Local nas diversas escolas, mas também algumas proposições que podem incentivar docentes na prática de se ensinar o passado de características regionais ou locais. 


\section{HISTÓRIA LOCAL: TECENDO DISCUSSÕES INICIAIS}

Durante muito tempo no Brasil, o ensino de História na educação escolar teve o objetivo de propagar as intenções das elites dominantes. Estas regulavam a difusão do conhecimento oficial nos períodos considerados ditatoriais, como demonstram os currículos e materiais educativos impressos. A disciplina de Estudos Sociais era a responsável por inteirar essa função, particularmente na segunda metade do século XX. Ao passar dos anos, sobretudo nas últimas décadas do século XX, as perspectivas do ensino de História foram sendo revisitadas e modificadas, repensando a História, as metodologias e as práticas de ensino, como assenta Bittencourt (2008, p. 99):

As propostas curriculares inserem-se em um momento importante da história do ensino de História. Cabe analisar com rigor metodológico os novos rumos projetados pelos currículos para se discernir o que efetivamente está em processo de mudanças e como atualmente ocorre "a seleção cultural" do conhecimento considerado essencial para os alunos.

A nova forma de se ensinar a disciplina de História não está mais preocupada em reproduzir somente o conhecimento escolar formal. Para além disso, propõe incentivar a formação crítica acerca das realidades, preparar o aluno para questionamentos plausíveis, reler os temas propostos nos Livros Didáticos pelo viés da humanização, alfabetização, difusão do respeito, da alteridade, de classe, gênero e regional. Freitas (2010), também acentua a importância do Ensino de História como disciplina capaz de estimular nos alunos a apreensão do passado de forma plural, o que auxilia a observar o acontecido sob diversas matizes. Ainda importa perceber que a construção da consciência histórica não se dá somente no ambiente e/ou no tempo escolar. Além dele, perpassa o anterior, o durante e o posterior. Antes de ele ser aluno, é cidadão. Neste sentido, compreendemos cidadania enquanto,

Participação social e política, assim como exercício de direitos e deveres políticos, civis e sociais, adotando, no dia-a-dia, atitudes de solidariedade, cooperação e repúdio às injustiças, respeitando o outro e exigindo para si o mesmo respeito; Posicionar-se de maneira crítica, responsável e construtiva nas diferentes situações sociais, utilizando o diálogo como forma de mediar conflitos e de tomar decisões coletivas. (BRASIL. MEC, 1998).

A partir da formulação dos Parâmetros Curriculares Nacionais (PCNs), de 1997, é possível entender a História como uma disciplina dinâmica capaz de entrelaçar tempos diferentes e que prepara os alunos para a retomada de consciência de sua formação histórica e cidadã. O ensino de História portanto, deve articular o macro e o micro dando visibilidade aos protagonistas anônimos, em suas narrativas, abordando além do ambiente escolar, o cotidiano familiar, a vida da cidade, do bairro e da região. Isto porque estão nos locais os registros em que a vida é tecida, em que as relações são construídas, onde as memórias se fazem presentes. A este respeito Guimarães (2011, p. 237) salienta que

A educação histórica, a formação da consciência histórica dos sujeitos não ocorre apenas na escola, mas em diversos lugares. Isso requer de nós uma relação viva e ativa com o 
tempo e o espaço do mundo no qual vivemos, pormenor que ele seja. O meio no qual vivemos traz as marcas do presente e de tempos passados. Nele encontramos vestígios, monumentos, objetos, imagens, manifestações de grande valor para a compreensão do imediato, do próximo e do distante. O local e o cotidiano, como locais de memória, são constitutivos, ricos de possibilidades educativas, formativas.

Se é a partir do cotidiano dos alunos que se constitui a razão do ensino da História Local, é preciso então, que ele seja trazido para as discussões em sala de aula. Discutir e debater não só o espaço, mas o espaço social que se firmou em temporalidades distintas, suas memórias e seus protagonistas. Debater os espaços em que os locais de memória deixam de ser apenas um conceito para serem observados mais detalhadamente.

Entende-se por local de memória aquele de sentido mais amplo: material, simbólico e funcional em que o aluno se sente parte do processo de reconstrução da própria história individual ou coletiva. Tal imbricação torna-se fundamental para que ele possa se situar no espaço e no tempo, compreendendo o meio em que vive como cidadão crítico (GUIMARÃES, 2011).

Neste sentido, a História Local pode propor um papel de forte decisão na construção de memórias que se inscreve ao longo do tempo. O cotidiano do aluno traduzido em seus espaços sociais constitui e é constitutivo de importantes dimensões de um tipo de viver, denominado por Quadros (2014, p. 25) como "sociointeracionista. O autor sugere que o estudante integrado a determinado grupo social (como a escola) precisa desenvolver um perfil questionador, um descobridor do mundo. Um mundo imenso, extenso, aquele para além dos limites da casa e da escola. Contudo, antes de ir ao encontro desse universo, é preciso conhecer o que o rodeia, sua história, suas raízes e referências, a identidade local capitaneada pela memória do lugar.

A questão da memória impõe-se por ser a base da identidade, e é pela memória que se chega à história local. Além da memória das pessoas, escrita ou recuperada pela oralidade, existem os "lugares da memória", expressos por monumentos, praças, edifícios públicos ou privados, mas preservados de todo e qualquer lugar de pessoas e de coisas, de paisagens naturais ou construídas torna-se objeto de estudo. (BITTENCOURT, 2008, p. 169).

Apresentar e debater os fatos locais é também um desafio. Bittencourt (2008, p. 169) pontua que é preciso certo distanciamento, exercitar uma certa imparcialidade. Por isso, o professor não deve

[...] simplesmente reproduzir a história do poder local e das classes dominantes, caso se limite a fazer os alunos conhecerem nomes de personagens políticos de outras épocas, destacando a vida e obra de antigos prefeitos e demais autores. Para evitar tais riscos, é preciso identificar o enfoque e a abordagem da história local que crie vínculos com memoria familiar do trabalho, da migração, das festas.

Para não cair na cilada da mera reprodução, a História Local deve ser ensinada em práticas pedagógicas que contemplem visitas presenciais ou virtuais a museus, praças, construções etc., por exemplo. Somada a isso, que os professores levem em conta a utilização de imagens do lugar, as fotografias das personagens locais, principalmente dos mais esquecidos, daqueles que 
não tiveram voz e vez; que os docentes observem os desenhos, que considerem os relatos, as vozes dos moradores mais antigos. Práticas de partilha e proposta pedagógica que evidenciam aspectos interdisciplinares para o ensino História Local mais próximos das realidades locais. Assim, vozes e imagens ganham espaços na construção dos saberes igualmente locais, contribuindo para a escrita de narrativas mais próximas e menos generalizantes.

Ensinar a História Local dessa forma é ainda um grande desafio. O ensino de História que leva em conta os acontecimentos e protagonistas locais é algo recente. Por ser novo, ainda traz desconfianças, ainda sofre críticas e receios. Nas décadas de 1970 e 1980, as propostas curriculares foram organizadas em círculos concêntricos, por meio dos estudos sociais gerais. Entre os anos de 1980 e 1990, predominou a história temática, sendo a história local colocada como uma das possibilidades de estratégia pedagógica incipiente, para garantir o mínimo de domínio do conhecimento histórico (DANTAS, SOUZA, 2018).

As temáticas locais para o ensino de História foram por muito tempo vigiadas e reprimidas. Os regionalismos entravam nas discussões como suporte de narrativas cujo foco eram os movimentos sociais, os debates contra o autoritarismo. O Local ou o regional eram coadjuvantes, não tinham ainda a centralidade das narrativas. Atualmente, as temáticas locais no Ensino de História deram um passo além e são abordadas em uma perspectiva interdisciplinar. A interdisciplinaridade se perpetua e se caracteriza, sobretudo, pelo envolvimento, compromisso e reciprocidade diante da diversidade dos saberes (FAZENDA, 1994). A Interdisciplinaridade tornava-se para a História Local uma grande aliada no compromisso da valorização dos sabres locais.

Tão complexo como conceituar a História Local é a definição de interdisciplinaridade. Segundo (JAPIASSU, 1994) faz-se necessário saber que, como não há um entendimento fechado sobre os níveis de integração entre as disciplinas, por consequência, não há uma consonância acerca do entendimento de interdisciplinaridade.

Ainda que pesquisadores em Educação discutam o conceito de interdisciplinaridade e cheguem a diferentes conclusões, o termo já aparecia na legislação educacional. Contudo, essa presença por vezes ocorria tão somente na legislação, não perpassando as vias da aplicabilidade de forma significativa no cenário educacional. Conforme Fazenda (1994), a legislação federal relativa à educação de 1961 e 1971 previa a formação dos indivíduos voltada ao trabalho e, portanto, na "integração" de competências próximas. A atual Lei de Diretrizes e Bases da Educação Nacional (Lei n 9.394 , de 20 de dezembro de 1996) dispõe sobre as normas para a organização do ensino brasileiro desde a Educação Infantil até o Ensino Superior. O princípio mais evidente nesta lei é o de que o ensino deve preparar tanto para a vida como para o trabalho. No seu artigo primeiro podemos perceber tal orientação: “Art. 1'. A educação abrange os processos formativos que se desenvolvem na vida familiar, na convivência humana, no trabalho, nas instituições de ensino e pesquisa, nos movimentos sociais e organizações da sociedade civil e nas manifestações culturais" (BRASIL, 1996).

Ainda, nos PCN's a interdisciplinaridade aparece como um princípio de articulação entre conteúdos e atividades. Em relação ao ensino de História, mais especificamente no que se refere aos aspectos temporais, por exemplo, de acordo com os PCNs, para os dois últimos ciclos do Ensino Fundamental, as diversas dimensões de tempo só são compreendidas em suas complexidades. Nesse sentido, não deve existir uma preocupação especial do professor em ensinar, formalmente, uma dimensão ou outra, mas trabalhar atividades didáticas diversificadas, de preferência em conjunto com outras áreas. (BRASIL, 1998, p. 97). 
O ensino de História, de acordo com os PCNs, deve ter seus conteúdos organizados a partir de eixos temáticos, procedimento que requer o desenvolvimento de práticas interdisciplinares. De acordo com os PCNs, a partir de problemáticas amplas, optou-se por organizar os conteúdos em eixos temáticos e desdobrá-los em subtemas, orientando estudos interdisciplinares e a construção de relações entre acontecimentos e contextos históricos no tempo. Além disso, os subtemas propostos devem estar relacionados a situações do presente. Cabe ao professor identificá-las e selecionar uma ou mais que possam orientar a escolha dos conteúdos a serem estudados. Tais escolhas podem e devem ser feitas em conjunto com outras disciplinas, enriquecendo o conhecimento que é por essência interdisciplinar. (BRASIL, 1998, p. 46-56).

Trabalhar a História Local como proposta interdisciplinar é entender que nenhuma disciplina existe sozinha; é compreender que eventos locais não acontecem isolados. A grande maioria dos fatos está intercalado, é responsivo e dinâmico. É perceber que por vezes, temáticas são comuns a várias disciplinas ou que um tema é gerado por outro. Contudo, interdisciplinaridade não é mistura, confusão, mas formas de se atentar sobre algo de modo diferenciado e que gera produção de conhecimentos (NEVES, 2015).

Por isso é importante priorizar um ensino de História que se aproxime da realidade do aluno afastando-o de narrativas gerais e de um conhecimento linear. A fuga do roteiro linear permite que o aluno seja agente transformador e não um mero figurante diante do processo histórico.

Nesse sentido [...] pretende se distanciar da velha narrativa de um passado morto, sem significado para a maioria dos homens e mulheres do presente, porém busca constituir um novo olhar histórico, onde o objeto de estudo se torne dinâmico, problematizador e mais próximo do pesquisador, consequentemente, possibilitando uma verdadeira relação entre o passado e o presente, que proporcione aos estudantes a elaboração de uma concepção critica acerca do mundo em que vive, capaz de suscitar possíveis transformações na sociedade em que estão inseridos. Nesse sentido, a proposta de História aqui apresentada, pretende se distanciar da velha narrativa de um passado morto, sem significado para a maioria dos homens e mulheres do presente, porém busca constituir um novo olhar histórico, onde o objeto de estudo se torne dinâmico, problematizador e mais próximo do pesquisador, consequentemente, possibilitando uma verdadeira relação entre o passado e o presente, que proporcione aos estudantes a elaboração de uma concepção critica acerca do mundo em que vive, capaz de suscitar possíveis transformações na sociedade em que estão inseridos. (SILVA, 2013, p. 05)

Neste sentido, é preciso despertar cada vez mais para a História Local. Face ao exposto, descrevemos nos próximos pontos um mapeamento da produção acadêmica sobre o História Local pautando-nos na necessidade de responder tais questionamentos: o que tem sido produzido nos últimos anos sobre esse tema? Quais os objetivos propostos? Quais as abordagens metodológicas empregadas? Quais resultados foram encontrados? Quais contribuições advêm desses estudos para o ensino de História Local? Fazemos dessas questões alicerces para as nossas inquietações de pesquisadores.

\section{A PRODUÇÃo ACADÊMICA SOBRE A HISTÓRIA LOCAL (2009-2019)}

Para responder as questões surgidas, apresentamos um levantamento da produção acadêmica sobre a História Local, o que pode ser enquadrado como um estado da arte ou estado 
do conhecimento. Segundo Ferreira (2002, p. 02) essas pesquisas são “[...] reconhecidas por realizarem uma metodologia de caráter inventariante e descritiva da produção acadêmica e científica sobre o tema que se busca investigar". É um passo rumo à consciência de não haver um conhecimento absoluto, procurando à luz de categorias, analisar as produções de um tema.

Esse termo é derivado do inglês em sua tradução literal e atua na possibilidade de contribuir para um campo de pesquisa, voltando o olhar às múltiplas perspectivas e pluralidades de enfoques que um objeto de estudo recebe. Seria, portanto, uma forma de inventariar e sistematizar determinada produção para se obter uma visão geral do que vem sendo produzido, favorecendo assim o direcionamento adequado dos esforços do pesquisador (ROMANOWSKI E ENS, 2006).

Ainda para fins de conceituação, entendemos com base nos estudos de Romanowski e Ens (2006) que esse estudo se trata de um estado da arte e não de um estado do conhecimento, por considerar que nossa investigação se dá em várias fontes de pesquisa, diferentemente deste último em que se aborda apenas um setor das publicações. E, para realizar esse mapeamento, definimos inicialmente os critérios para a seleção do material que compõe o corpus do nosso estudo. Interessava-nos, então, descobrir as produções a respeito da História Local no Brasil.

Para realizarmos esse mapeamento, definimos inicialmente os critérios para a seleção do material que compõe o corpus do nosso estudo, privilegiando, assim, a produção acadêmica entre os anos de 2009 a 2019. Tendo definido o nosso recorte temporal, estabelecemos as nossas fontes de pesquisas: o Catálogo de Teses e Dissertações da CAPES, a Revista de História da USP, A Revista História e Ensino e o Projeto Político Pedagógico de três escolas de Mossoró - RN. Por fim, estabelecemos o nosso descritor como "História Local", haja vista é um tema muito específico e uma busca simplificada nesses termos já nos interessaria.

A seleção dos trabalhos foi feita por meio da leitura do título, por anunciar a informação principal de um estudo; da leitura do resumo, que quando bem elaborado aponta o objetivo principal da investigação, a metodologia, o instrumento teórico, a coleta e o tratamento de dados, os resultados e as conclusões; e a leitura das palavras-chave, por serem termos centrais da pesquisa (FERREIRA, 2002).

A primeira fonte de pesquisa que integra esse estado da arte é o Catálogo de Teses e Dissertações da CAPES, bastante conhecido por possibilitar um panorama das produções acadêmicas a nível de pós-graduação. O Catálogo de Teses e Dissertações atua como um sistema de busca bibliográfica por conservar um vasto acervo digital de teses de doutorado e dissertações de mestrado de programas reconhecidos desde o ano de 1987. É importante salientar também que o sistema possui como referência a Portaria no 13/20064.

Para a seleção, fizemos uso do descritor "História Local", objeto de nosso estudo. A busca inicial resultou em 175.067 trabalhos. Em seguida, adicionamos o primeiro filtro, que afunilou para 163.420 trabalhos. Com o recorte temporal aplicado, de 2009 a 2019, reduzimos esses resultados para o montante de 104.320. Na aplicação do filtro 'grande área do conhecimento', optamos por Ciências Humanas e Multidisciplinar, resultando em 12.688 trabalhos. Por fim, na área de conhecimento e na área de avaliação, selecionamos a opção 'Ensino e História', que nos conduziu a 596 trabalhos, que agrupamos na Tabela 1 apenas em virtude de ano e tipo do trabalho. 
Tabela 1 - Quantitativo de trabalhos encontrados no Catálogo de Teses e Dissertações da CAPES

\begin{tabular}{c|ccc} 
Ano & Dissertação & Tese \\
\hline 2009 & 115 & 52 & 49 \\
2010 & 105 & 42 & 35 \\
2011 & 96 & 178 & \\
2012 & 102 & 418 &
\end{tabular}

Fonte: Produção dos autores (2020).

Com esses 596 trabalhos compondo nosso inventário, fizemos a leitura também em função de título, resumo e palavras-chave, buscando pelos nossos descritores. Dessa forma, não encontramos nenhum trabalho que fosse correspondente. Essa era a fonte de pesquisa que mais nos interessava, uma vez que a História Local é nosso objeto de estudo, nos importando compreender como está a produção sobre esse tema na pós-graduação. Relatamos também a dificuldade em encontrar determinados trabalhos por serem anteriores à Plataforma Sucupira, e assim, seu acesso não ser facilmente disponibilizado, tendo que buscar em bibliotecas em que foram depositados.

A segunda fonte de pesquisa trata-se da Revista de História da USP, fundada em 1950 pelo docente Eurípedes Simões de Paula e considerado um dos mais antigos periódicos acadêmicos do Brasil com especialização nessa disciplina. A Revista é publicada pelo Departamento de História da Faculdade de Filosofia, Letras e Ciências Humanas da Universidade de São Paulo (DH/FFLCH/USP) e tem como missão principal divulgar artigos em português e espanhol, considerando que estes devem ser originais inéditos ou traduzidos, compreendendo resenhas e edições crítica de fontes na área de História e afins.

O principal objetivo da revista é contribuir com o debate acadêmico na área das Ciências Humanas. A periodicidade até 2016 era semestral, contudo, a partir de 2017 passou a ser anual. A publicação conta com o apoio financeiro dos dois programas de pós-graduação do Departamento de História da Faculdade de Filosofia, Letras e Ciências Humanas (FFLCH) - História Social e História Econômica - e do Programa de Apoio às Publicações Periódicas Científicas da USP. Como nosso recorte temporal estabeleceu-se entre os anos de 2009 a 2019, apresentamos abaixo o número de trabalhos (artigos e resenhas) compreendidos no período:

Tabela 2 - Quantitativo de trabalhos encontrados na Revista de História da USP

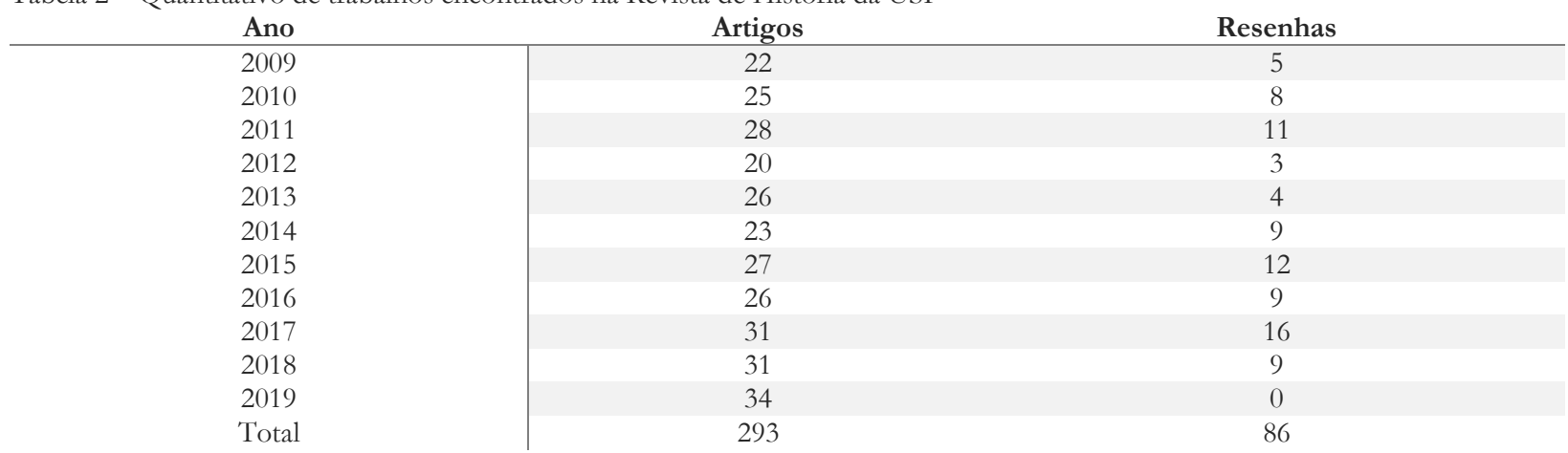

Fonte: Produção dos autores (2020).

Com esses 379 trabalhos compondo nosso inventário, fizemos a leitura a partir dos título, resumo e palavras-chave. Dessa forma, não encontramos nenhum trabalho que mencionasse a "História Local". Nossa terceira fonte de pesquisa foi a Revista História e Ensino. A justificativa dessa escolha se dá pelo seu amplo campo de discussão: ensino de história, educação 
histórica, metodologias para o ensino de história, aprendizado histórico, didática da história, construção do saber histórico escolar, história da disciplina de história, estágio de história, ensino de história extraescolar, história da educação, currículo de história, cognição histórica, relações entre ensino de história e história pública, formação do professor de história e história da infância e da juventude.

Essa revista é destinada tanto aos alunos do curso de História como aos professores de todos os níveis de ensino e pesquisadores do ensino de História. Quanto à periodicidade, tratase de uma revista de fluxo semestral e está em publicação desde 1995. Os artigos apresentam resultados de pesquisas e relatos de experiências didático-pedagógicas e devem também primar pelo ineditismo da investigação ou da abordagem. Para atendermos ao nosso recorte temporal, analisamos as publicações de 2009 a 2019, totalizando o que podemos verificar na tabela abaixo.

\begin{tabular}{c|c} 
Tabela 3 - Quantitativo de trabalhos encontrados na Revista de História e Ensino. & Artigos \\
Ano & 12 \\
\hline 2009 & 8 \\
2010 & 19 \\
2011 & 26 \\
2012 & 27 \\
2013 & 21 \\
2014 & 29 \\
2015 & 26 \\
2016 & 20 \\
2017 & 26 \\
2018 & 44 \\
2019 & 258 \\
Total &
\end{tabular}

Fonte: Produção dos autores (2020).

Dos 258 trabalhos, encontramos os que tematizavam o nosso objeto de pesquisa. São eles: História Local e Identidade: um estudo de caso na perspectiva da Educação Histórica (2012); O ensino da História Local e Itinerários da Educação em Alagoas: diálogos possíveis (2013); A história do e no Ceará: uma reflexão metodológica sobre os livros didáticos (2013); Estratégias de ensino da História e dos Estudos Sociais no $1^{\circ}$ ciclo do Ensino Básico (2013); Vestígios e Memórias: História Local e o Ensino de História nos anos iniciais do Ensino Fundamental (2014); História e Memória: pesquisa-ação-participativa no ensino da História Local (2015); Os desafios da valorização da Memória e História Local em Cambira (PR) a partir do estudo das interações sociais nos limites paroquiais (2015); e, por fim, O ensino de História e o protagonismo discente: desafios na Amazônia Rondoniense (2016).

Por fim, como quarta fonte de pesquisa, analisamos o Projeto Político Pedagógico de três escolas públicas da Secretaria Municipal da Educação da cidade de Mossoró - RN, para verificar se, entre os eixos norteadores e concepções pedagógicas, se entre as competências e habilidades no ensino fundamental do $1^{\circ}$ ao $9^{\circ}$ ano, havia referência ao ensino de História Local. Encontramos somente dois pontos que tangenciavam a temática: a) fazer com que o aluno saiba se situar no tempo histórico e nos espaços geográficos; e b) mostrar a realidade passada e presente na sua diversidade, na construção e reconstrução de fatos e personagens marcantes a cada época. Frases demasiadamente gerais que tratam de um tema tão atual e premente revelam como a História Local é compreendida pelos agentes responsáveis pela Educação Pública Municipal.

Importa, por fim, destacar que finalizamos nossas quatro fontes, analisando um total de 
1.236 trabalhos tendo como filtro-descritor os títulos, os resumos e as palavras-chave. Desse montante, somente oito estudos completos (artigos) contemplaram o tema, os objetivos, os aspectos metodológicos, os resultados, as conclusões, que se mostraram convergentes ao propósito de nossa pesquisa.

\section{RESULTADOS E DISCUSSÕES}

Antes de nos aprofundar nas discussões, privilegiamos trazer uma síntese de cada um dos trabalhos inventariados para deles saber melhor o que cada um trata, seus enfoques e abordagens.

O artigo História Local e Identidade: um estudo de caso na perspectiva da Educação Histórica traz resultados parciais a respeito de como as concepções de identidade são abordadas nas aulas de História Local por professoras do $3^{\circ}$ ano do Ensino Fundamental de uma escola da rede municipal de Campo Largo - PR. Trata-se de uma pesquisa qualitativa, um estudo de caso cujos dados foram coletados mediante questionários, observações em sala de aula e entrevistas com as professoras. Os resultados parciais apontaram certo empenho por parte dos docentes em ministrar a História Local. Entre os alunos, havia interesse que a temática fosse mais explorada em sala de aula.

O segundo artigo tem por título $O$ ensino da História Local e itinerários da disciplina tópicos de História da educação em Alagoas: diálogos possiveis. Apresenta como objetivo principal registrar as experiências vividas na formação de professores/as, articulando-as com as discussões voltadas para o debate epistemológico do conhecimento histórico escolar. Também procurava verificar a importância do ensino da História Local na formação de estudantes do curso de pedagogia. A metodologia adotada foi observação participante. Como resultado, a pesquisa mostrou que a História Local não era tematizada em profundidade ao longo da escolarização. Havia grande esperança entre os discentes que a História Local fosse de fato implementada nos currículos de História.

O terceiro artigo, História do e no Ceará: uma reflexão metodológica sobre os livros didáticos (18891940, discorreu sobre a História do Ceará presente nos compêndios do período de 1889 até 1940. Os resultados apontaram que a influência europeia na formação escolar dos cidadãos foi preponderante, o que repercutiu também na maneira de se escrever a História do Ceará alinhada às generalizações. Não são apresentadas proposições de estudos futuros.

O quarto artigo tem por título Estratégias de Ensino de História e dos Estudos Sociais no $1^{\circ}$ ciclo do Ensino Básico. Neste, considerando a transversalidade e interdisciplinaridade de que se reveste a área disciplinar curricular de Estudo do Meio Social no $1^{\circ}$ Ciclo do Ensino Básico, procurou-se ter como âncora a apresentação de um diverso conjunto de resultados de investigações desenvolvidas em Centros Escolares do Conselho de Viana do Castelo no quadro das atividades pedagógicas. A metodologia utilizada tratou de uma investigação-ação. Dentre os vários resultados, constatou-se que os alunos, não obstante à simplicidade e pureza das suas ideias, mostraram uma consciência aproximada da realidade. Não são apresentadas proposições de estudos futuros.

O quinto artigo, intitulado Vestígios e Memórias: História Local e o Ensino de História nos anos iniciais do Ensino Fundamental, desenvolveu uma reflexão sobre a contribuição da História Local no Ensino de História nos Anos Iniciais, a partir de uma experiência desenvolvida com os acadêmicos do $7^{\circ}$ período do curso de Pedagogia do Centro de Estudos Superiores de Parin- 
tins (CESP), da Universidade do Estado do Amazonas (UEA). O texto insinua que a fonte dos dados se deu através de entrevistas entre o corpo docente e discente. Também não são apresentadas proposições de estudos futuros.

O sexto artigo, por sua vez, tem por título História e Memória: pesquisa-ação-participativa no Ensino da História Local. Foi pautado pelo método de pesquisa-ação-participativa com jovens do ensino médio de uma escola de Santa Catarina, envolvendo a disciplina de História. No período de um ano (2013-2014), foi aplicada uma metodologia de ensino envolvendo teoria e prática no estudo da memória histórica local, por meio de coleta de depoimentos gravados, revisão bibliográfica, análise de fotografias, objetos antigos e representação teatral. Quanto aos resultados, foi constatado que o projeto tornou o espaço escolar mais atraente para os alunos, contribuindo para a diminuição da evasão escolar, além da integração família e escola nas atividades escolares. As proposições de estudos futuros não foram apresentadas.

Já o sétimo artigo, intitulado Os desafios da valorização da Memória e História Local em Cambira (PR) a partir do estudo das interações sociais nos limites paroquiais, é fruto de um projeto de extensão denominado "História Local: a Educação Patrimonial e o Exercício da Cidadania", lançado em 2008 com o apoio da Secretaria de Estado da Ciência, Tecnologia e Ensino Superior (SETI). Como resultado, constatou-se o entrelaçamento entre a memória e as experiências vivenciadas em torno das celebrações locais da Igreja Católica. Assim, é apresentada a valorização da memória e da história local a partir do estudo das interações sociorreligiosas. Não são apresentadas proposições de estudos futuros.

Por fim, o oitavo artigo, O Ensino de História e o Protagonismo Discente: desafios na Amazônia Rondoniens, problematiza as questões observadas durante as atividades do Programa Institucional de Bolsas de Iniciação à Docência (PIBID), realizadas no $7^{\circ}$ ano do ensino fundamental de uma escola na Amazônia rondoniense. A partir das informações levantadas com entrevistas semiestruturadas e observações, o artigo refletiu acerca da denominada perspectiva "tradicional" e das "novas" possibilidades metodológicas do fazer histórico em sala de aula. Não são apresentadas proposições de estudos futuros.

De posse dessas informações, a princípio, planificamos os dados no Quadro 3. Nossa tentativa foi provocar a compreensão sobre os próprios aspectos sociais que envolvem o custeio/financiamento das pesquisas. Romanowski e Ens (2006) trazem a importância de fazer comparações entre regiões para identificar problemas comuns, políticas, a partir das similaridades e integração desses resultados. 
Quadro 3 - Informações sobre os trabalhos do corpus

\begin{tabular}{|c|c|c|c|c|c|}
\hline Ano & Título & IES & Forma & Região & Financiamento \\
\hline 2012 & $\begin{array}{l}\text { História Local e Identidade: um estudo de caso } \\
\text { na perspectiva da Educação Histórica; }\end{array}$ & $\begin{array}{l}\text { Universidade Tuiuti } \\
\text { do Paraná }\end{array}$ & Privada & PR & Não \\
\hline 2013 & $\begin{array}{l}\text { O ensino da História Local e Itinerários da } \\
\text { Educação em Alagoas: diálogos possíveis; }\end{array}$ & $\begin{array}{l}\text { Universidade Fede- } \\
\text { ral de Alagoas }\end{array}$ & Pública & $\mathrm{AL}$ & Não \\
\hline 2013 & $\begin{array}{l}\text { A história do e no Ceará: uma reflexão meto- } \\
\text { dológica sobre os livros didáticos; }\end{array}$ & $\begin{array}{l}\text { Universidade Fede- } \\
\text { ral do Ceará }\end{array}$ & Pública & CE & Sim \\
\hline 2013 & $\begin{array}{l}\text { Estratégias de ensino da História e dos Estu- } \\
\text { dos Sociais no } 1^{\circ} \text { ciclo do Ensino Básico; }\end{array}$ & $\begin{array}{l}\text { Instituto Politécnico } \\
\text { de Viana do Castelo }\end{array}$ & Público & Portugal & Não \\
\hline 2014 & $\begin{array}{l}\text { Vestígios e Memórias: História Local e o En- } \\
\text { sino de História nos anos iniciais do Ensino } \\
\text { Fundamental; }\end{array}$ & $\begin{array}{l}\text { Universidade do Es- } \\
\text { tado do Amazonas }\end{array}$ & Pública & $\mathrm{AM}$ & Não \\
\hline 2015 & $\begin{array}{l}\text { História e Memória: pesquisa-ação-participa- } \\
\text { tiva no ensino da História Local; }\end{array}$ & $\begin{array}{l}\text { Universidade do } \\
\text { Contestado }\end{array}$ & Privada & SC & Não \\
\hline 2015 & $\begin{array}{l}\text { Os desafios da valorização da Memória e His- } \\
\text { tória Local em Cambira (PR) a partir do estudo } \\
\text { das interações sociais nos limites paroquiais; }\end{array}$ & $\begin{array}{l}\text { Universidade Fede- } \\
\text { ral do Rio Grande do } \\
\text { Sul }\end{array}$ & Pública & RS & Não \\
\hline 2016 & $\begin{array}{l}\text { O ensino de História e o protagonismo dis- } \\
\text { cente: desafios na Amazônia Rondoniense. }\end{array}$ & $\begin{array}{l}\text { Universidade Fede- } \\
\text { ral de Rondônia }\end{array}$ & Pública & $\mathrm{RO}$ & Sim \\
\hline
\end{tabular}

Fonte: Autores, 2020.

Os trabalhos foram desenvolvidos do ano de 2012 a 2016, o que denota a falta de trabalhos mais recentes. Depois, percebemos que a maioria dos artigos é desenvolvido em instituições públicas, mostrando, pois, o protagonismo das instituições públicas nas pesquisas e produção científica. Além disso, a maior parte é feita sem financiamento.

A começar pelos objetivos dos trabalhos, vemos que a maior parte deles apontava para a valorização - mediante fontes e métodos capazes de valorizar a história local- do patrimônio cultural e ambiental, que reverberaram na tentativa do exercício da cidadania..

De comum, as pesquisas tematizam a História Local em suas práticas pedagógicas em sala de aula, e como o seu ensino relaciona-se com a memória e os alunos? Já a respeito do marco teórico, os principais autores apontados acerca da História Local foram Levi (1992); Alberti (2004); Fernandes (2015); Bittencourt (2010); Alves (2010); Goubert (1988); Guimarães (2011); Nikitiuk (2012); e Toledo (2012). Em relação à metodologia, a maior parte faz uso de uma abordagem qualitativa, diante de estudos investigativos. Quanto à coleta de dados, é feito uso de entrevistas, questionários e observações em sala de aula.

Em relação aos resultados, de cunho reivindicatório, observou-se a necessidade de um amparo curricular que contemple o ensino a História Local de forma menos transversal, ou seja, que ela seja também um eixo norteador dos estudos.

Sabemos, por fim, que toda ação desencadeia reação. Acreditamos na vinculação do Ensino com Pesquisa para possíveis melhorias.

\section{CONSIDERAÇÕES FINAIS}

Fractais, no âmbito da geometria, constituem formas que, mesmo quando repartidas em porções menores, preservam suas características físicas. Pensamos o Ensino de História Local como um fractal, pois, por mais que o tempo passe e ocorram transformações, é na singularidade de um lugar que os registros da História permanecem. Por mais gerais que sejam as apreensões, por mais universais que sejam os conceitos ou as teorias de cunho historiográfico, as fontes descansam em espaços pontualmente localizados, facilmente mapeados e encontrados. 
Compreendemos que cada lugar guarda uma historicidade, preserva um detalhe da tida História Universal. Assim, por menor que seja, o local conserva a magnitude do acontecido, a grandeza das particularidades que lidas, interpretadas e arguidas sob vários aspectos, revelamse espaços possíveis onde se desencadeia a escrita da História.

O percurso dessa pesquisa foi motivado por um incômodo, uma pergunta que perambulava qual um fantasma e que precisava ser aclarado: como a História Local é ensinada em sala de aula? A partir dessa pergunta-problema foi preciso pensar nos passos que requer uma investigação acadêmica para avaliar sua exequibilidade. Escolhemos então, consultar o Catálogo de Teses e Dissertações da CAPES, a Revista de História da USP, a Revista História e Ensino e o Projeto Político Pedagógico de três escolas de Mossoró - RN com o objetivo de analisar o que já tinha sido produzido acerca do Ensino da História Local. A escolha do Catálogo de Teses e Dissertações e das Revistas é justificada por elas serem referências de pesquisas utilizadas por grande parte dos pesquisadores. É importante ressaltar que há inúmeros periódicos de prestígio e de reconhecimento internacional e que não foram contemplados nesta pesquisa. A escolha é apenas fruto de uma amostragem, por isso pode apresentar resultados parciais, incompletos. De toda forma, serviu para diagnosticar 'se' e 'como' a temática da História Local é abordada. Semanas inteiras de leituras apontaram para a necessidade de catalogação dos dados, para, posteriormente, sobre eles arguir. Os dados foram planificados e mostrados em quadros que facilitam a visão do conjunto.

A dinâmica estrutural e estética da pesquisa dada pela confecção de tabelas, pela subdivisão de temas e subtópicos obedecem a uma forma a apresentação de uma pesquisa qualitativa. Independente do aspecto delineado, gostaríamos de agora, fazer algumas considerações acerca da temática escolhida, propondo igualmente, métodos de aplicação da História Local na disciplina de História.

O Ensino de História Local é uma realidade em consolidação. Muitos passos já foram dados, mas há inúmeros a serem trilhados. Permanece, no entanto, ainda uma imprecisão de cunho legislativo e oficial que facilite a inserção dos temas locais nos currículos da disciplina de História. Outro vazio diagnosticado pelas leituras dos trabalhos diz respeito a displicências dos Livros Didáticos em apresentar ou sugerir temáticas de vertente regional ou local, nos conteúdos de História. Porque a maioria dos professores se atem àquilo que os Didáticos oferecem, não se sente encorajada ou capacitada para apresentar conteúdos locais e relacionálos aos gerais.

O presente artigo evidencia a importância da valorização dos espaços em que alunos e professores vivem, convivem, se socializam e costuram suas relações. A evidência não se reduz à simples constatação da existência das espacialidades, mas pontua a iniciativa de transformá-las em conteúdo de cunho historiográfico, responsivo às demandas e problemas pertinentes à formação integral do aluno. Isto porque, compreendemos que a História presentifica os atos, os acontecimentos, as ideias, as mentalidades etc. ganhando sopros de vida e repercussão sociocultural, no decurso do tempo e inserida em um contexto espacial.

A presente pesquisa não esgota a temática nesses poucos parágrafos. Apenas, cutucamos o problema, para alertar acerca das potencialidades investigativas que o assunto sugere. Para além disso, a História Local pode ser ensinada em sala de aula aproveitando as fontes visuais (fotografias, ilustrações, desenhos, pequenos filmes) ou se servindo da memória dos moradores locais. Outra possibilidade é convidar alunos para revisitar as festas, as comemorações públicas da cidade e ensiná-los a apreender que nestes eventos há uma plausibilidade e um 
lastro de uma historiografia local que não pode ser relegada ou negligenciada.

\section{REFERÊNCIAS}

AMORIM, R. M.; Santos, A. M. O ensino da História Local e Itinerários da Educação em Alagoas: diálogos possíveis. Revista História \& Ensino, Londrina, v. 19, n. 1, 2013.

ARAÚJO, Fátima. Maria Leitão. A história do e no Ceará: uma reflexão metodológica sobre os livros didáticos (1889 - 1940). Revista História \& Ensino, Londrina, v. 19, n. 2, 2013.

ARAZANI, Alessandro. Os desafios da valorização da Memória e História Local em Cambira (PR) a partir do estudo das interações sociais nos limites paroquiais. Revista História \& Ensino, Londrina, v. 21, n. 1, 2015.

BAUER, Carlos. Teoria da História: A Educação no Brasil.1. ed. Jundiaí, SP: Paco Editorial, 2012.

BIANCHEZZI, Clarice; Coelho, A. M.; Silva, D. C.; Souza, E. S. Vestígios e Memórias: História Local e o Ensino de História nos anos iniciais do Ensino Fundamental. Revista História \& Ensino. Londrina, v. 20, n. 2, 2014.

BITTENCOURT, C. M. F. Ensino de História: fundamentos e métodos. 2. ed. São Paulo: Cortez, 2008.

BRASIL, Lei de Diretrizes e bases da Educação Nacional - LDB, 1996. Disponível em: <http://portal.mec.gov.br/secad/arquivos/pdf/ldb.pdf> Acesso em 10 jan. 2020.

BRASIL. Ministério da Educação e Cultura. Parâmetros curriculares da educação. Brasília: MEC, 1998. Disponível em: <http://portal.mec.gov.br/seb/arquivos/pdf/livro01. pdf $>$. Acesso em 10 de jan. 2020.

BRASIL. Base Nacional Comum Curricular (BNCC). Brasília: MEC. 2017. Disponível em: <http://basenacionalcomum.mec.gov.br/images/BNCC_20dez_site.pdf> Acesso em: 13 fev. 2019.

DANTAS, A. R. P.; SOUZA, F. C. S. História local e formação da consciência histórica na educação básica. In: Ensino na educação básica. Natal: IFRN, 2018.

FAZENDA, Ivani A. Interdisciplinaridade: História, teoria e Pesquisa. São Paulo: Papirus, 1994.

FERREIRA, Norma Sandra de Almeida. As pesquisas denominadas "estado da arte". Educação \& Sociedade, Campinas, v. 23, n. 79, p. 257-272, 2002.

FREIRE, Paulo Pedagogia da autonomia: Saberes necessários à prática educativa. São Paulo: Paz e Terra, 1996. (Coleção Leitura).

FREITAS, I. Fundamentos teórico-metodológicos para o ensino de História. São Cristóvão: Editora UFS, 2010.

GERMINARI, G.; Buczenko, G. História local e identidade: um estudo de caso na perspectiva da Educação Histórica. Revista História \& Ensino, Londrina, v. 18, n. 2, 2012.

GUIMARÃES, S. Didática e prática de ensino de História. 12. ed. Campinas/SP: Papirus, 2011.

JAPIASSU, H. A questão da interdisciplinaridade. Texto base da palestra proferida no Seminário Internacional sobre Reestruturação Curricular, promovido pela Secretaria Municipal de Educação de Porto Alegre, 1994. Disponível em: http://smeduquedecaxias.rj.gov.br/ne ad/Biblioteca/Forma $\%$ C3\%A7\%C3\%A30\%20Continuada/Artigos \%20Diversos/interdisciplinaridade-japiassu.pdf. Acesso em 10 jan. 2020. 
LIMA, Soeli R. História e Memória: pesquisa-ação-participativa no ensino da História Local. Revista História \& Ensino, Londrina, v. 21, n. 1, 2015.

MARQUES, G.; Barroso, A.; Pereira, Ana C.; Matos, C. J.; Machado, Filipa; Pereira, M. Estratégias de ensino da História e dos Estudos Sociais no $1^{\circ}$ ciclo do Ensino Básico; Revista História \& Ensino, Londrina, v. 19, n. 1, 2013.

NEVES, Carmen. Formação de professores da educação básica e pós-graduação: A interdisciplinaridade necessária. In: PHILIPP JR., Arlindo; FERNANDES, Valdir (Orgs.). Práticas da Interdisciplinaridade no Ensino e Pesquisa. Barueri. SP: Manole, 2015, p.55-67.

PESOVENTO, A.; Rodrigues, D. P.; Hell, J. K. P. O ensino de História e o protagonismo discente: desafios na Amazônia Rondoniense. Revista História \& Ensino, Londrina, v. 22, n. 2, 2016.

QUADROS, Claudemir de. A Relevância da didática para uma epistemologia da história. In: MONTEIRO, Ana Maria e PENNA, Fernando de Araújo et al (Org). Pesquisa em ensino: entre desafios epistemológicos e apostas políticas. Rio de Janeiro: Mauad X; FAPERJ, 2014, p. 119-151.

ROMANOWSKI, Joana Paulin; ENS, Romilda. Teodora. As pesquisas denominadas do tipo "estado da arte" em educação. Diálogo Educacional, Curitiba, v. 6, n. 19, p. 37-50, 2006.

SILVA, Wagner Rodrigues. Construção da interdisciplinaridade no espaço complexo de ensino e pesquisa. Cadernos de pesquisa, São Paulo, v. 41, n. 143 maio/ago. 2011. 